\title{
Integrated Traffic Information Service System for Public Travel Based on Smart Phones Applications: A Case in China
}

\author{
Chonghua Zhou \\ SHANGHAI YANHUA SMARTECH GROUP CO., LTD, Shanghai, China \\ E-mail: zhouchonghua@chinaforwards.com \\ Zhiyong Weng \\ SHANGHAI YANHUA SMARTECH GROUP CO., LTD, Shanghai, China \\ E-mail:wengzhiyong@chinaforwards.com \\ Chen Xu \\ TONGJI ARCHITECTURAL DESIGN (GROUP) CO., LED, Shanghai, China \\ E-mail:piano_2009@126.com
}

Zhizhe Su

Thi Shanghai Consultants INC, Shanghai, China

E-mail:su@msl.thi.com.tw

\begin{abstract}
Owing to its outstanding performance and rich features, Smart phones have been the rapid development over the past decade, more and more people love to use its mobile Application to process the day-to-day affairs instead of PC, including the normal call and Short Messaging Service, Personal Information Management, send and receive e-mail, browse Web, multimedia Applications and online shopping. In April 2011, the Taipei people began to use the free smart phone Apps "Good Travel in Taipei" to check the realtime traffic information of Taipei City Department of Transportation and get the best route plans according to your location, the Apps software brings together road, bus, subway, bike, high-speed rail, airport, parking and other traffic information, can be easily, simple and fast delivery to the public. The papers will introduce the case of "Good Travel in Taipei" firstly, then Zhengzhou is as an example in China to illustrate the Application of integrated traffic information service system for public travel based on smart phones, we hope it can provide a reference for the future construction of the similar mobile App of traffic information service system in the other cities for public travel.
\end{abstract}

Index Terms - Smart Phones, Mobile Application, Traffic Information Service for Public Travel

\section{Background}

The smart phone is a general term for the phones, which "like a PC, with an independent operating system, can install software, games, and other third-party programs provided by service providers by the user, through those programs continuously expanding the function of the phone, and accessing network wirelessly through the mobile communication network". Since the launch of the Casio B.O.S.S. in 1989, the smart phone has been the rapid development, and gradually become the future trend of the mobile phone. It is predicted [1] that to 2013, the number of the internet users using mobile will reach 1.78 billion worldwide, more than the number of the users using PC. Simultaneously there will be total 1.82 billion devices Including smart phones and other internet phone. Accompanied with the rapid development of smart phones, the mobile Applications showing a soaring development trend, instead of the PC to handle part of the daily affairs, including personal information management, calendar notes, scheduling task, multimedia Applications, browsing the web to send and receive e-mail, online shopping and so on. According to the report of the market research firm Juniper Research [2]: in 2015, the numbers of the smart phone software downloads will reach 25 billion. It is foreseeable that the mobile Applications will pervade every aspect of our lives and indispensable to people's lives. The traffic information is published to the general public free through smart phone's App. This papers based on the analysis of "Taipei good line" system, aimed at the current situation and actual demand of the 
Zhengzhou traffic information, proposed the system architecture of Zhengzhou traffic information service for public travel based on smart phones Apps, and deepening design its function.

\section{II. “Good Travel in Taipei” Case Review [3]}

\subsection{Travel in Flora Expo}

2010 International Flora Exposition was hold in Taipei 2010, referred to the Taipei Flower Expo. To query traffic information and browse the propaganda website of Taipei Flower Expo for people, Taipei City Department of Transportation and Jing Yi Technology Company developed an Apps "Travel in Flora Expo" in IOS and Android for people to free download in 2010. From Travel in Flora Expo launched in early October 2010 to the end of 2010, Travel in Flora Expo had be download 40000 times in IOS and 9000 times in
Android. Travel in Flora Expo's functional architecture is shown in Fig.1.

To meet the growth demand of the traffic information and smart phones with different operating system, and With Taipei Flower Expo end operations on April 25, 2011, The Taipei government expand the App (Realtime Traffic Information Smartphone Application Program) in three aspects: (1) launched App "Good Travel in Taipei" combined of LBS (Location Based Service) function; (2) provide personalized traffic information service: "Good Travel in Taipei" mainly have two personalized traffic information service, one is " Remind of bus arrival", the other is "Real-time traffic condition of the route frequently used"; (3)more choice of smart phones operating platform, such as IOS, Android, Windows phone.

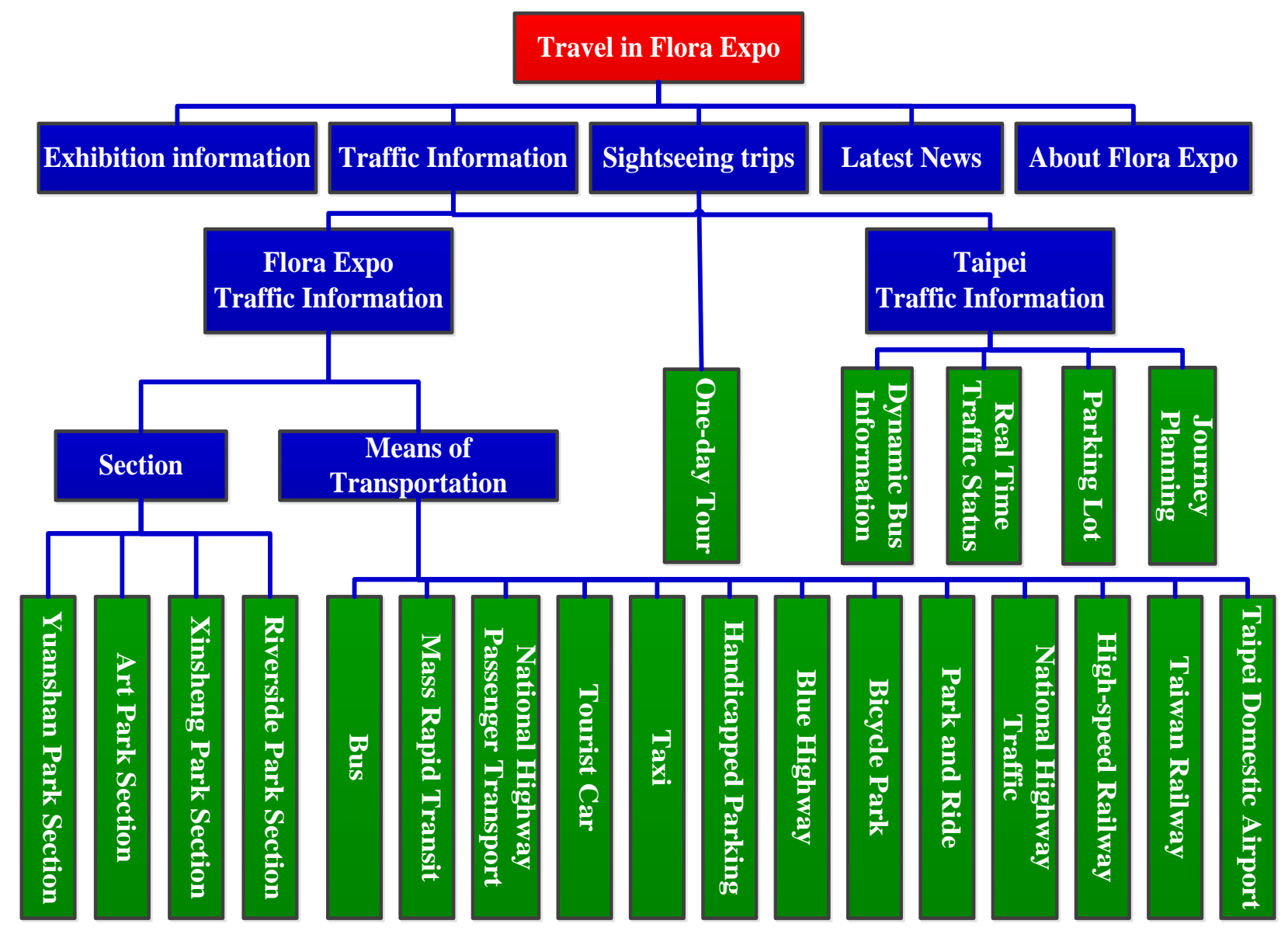

Fig. 1: Travel in Flora Expo's Functional Architecture

\section{2 "Good Travel in Taipei"}

\subsubsection{System Architecture}

"Good Travel in Taipei" App combining the LBS positioning technology and the dynamic path planning based on GPS (Global Positioning System), covering different transport information, provides a convenient Taipei traffic information query method, making users a smart phone in hand, a good travel in Taipei. "Good Travel in Taipei" App's system architecture features shown in Fig.2: 


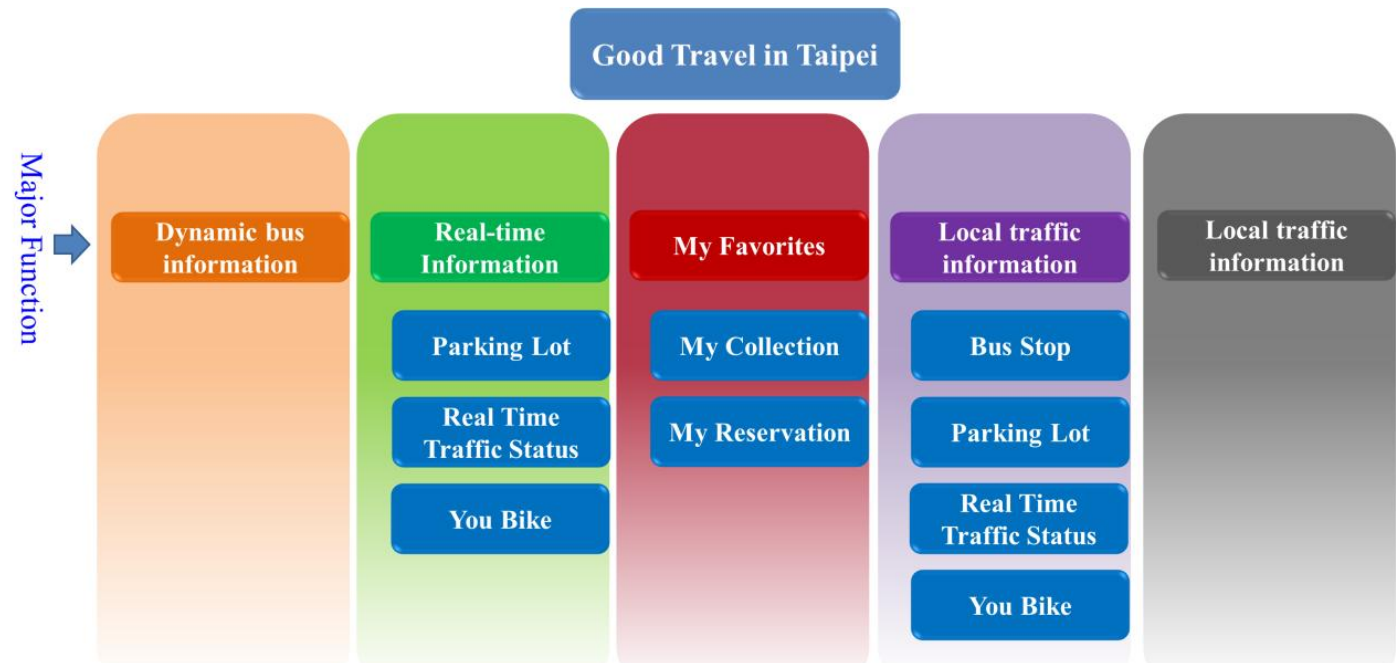

Fig. 2: Good Travel in Taipei’s Functional Architecture

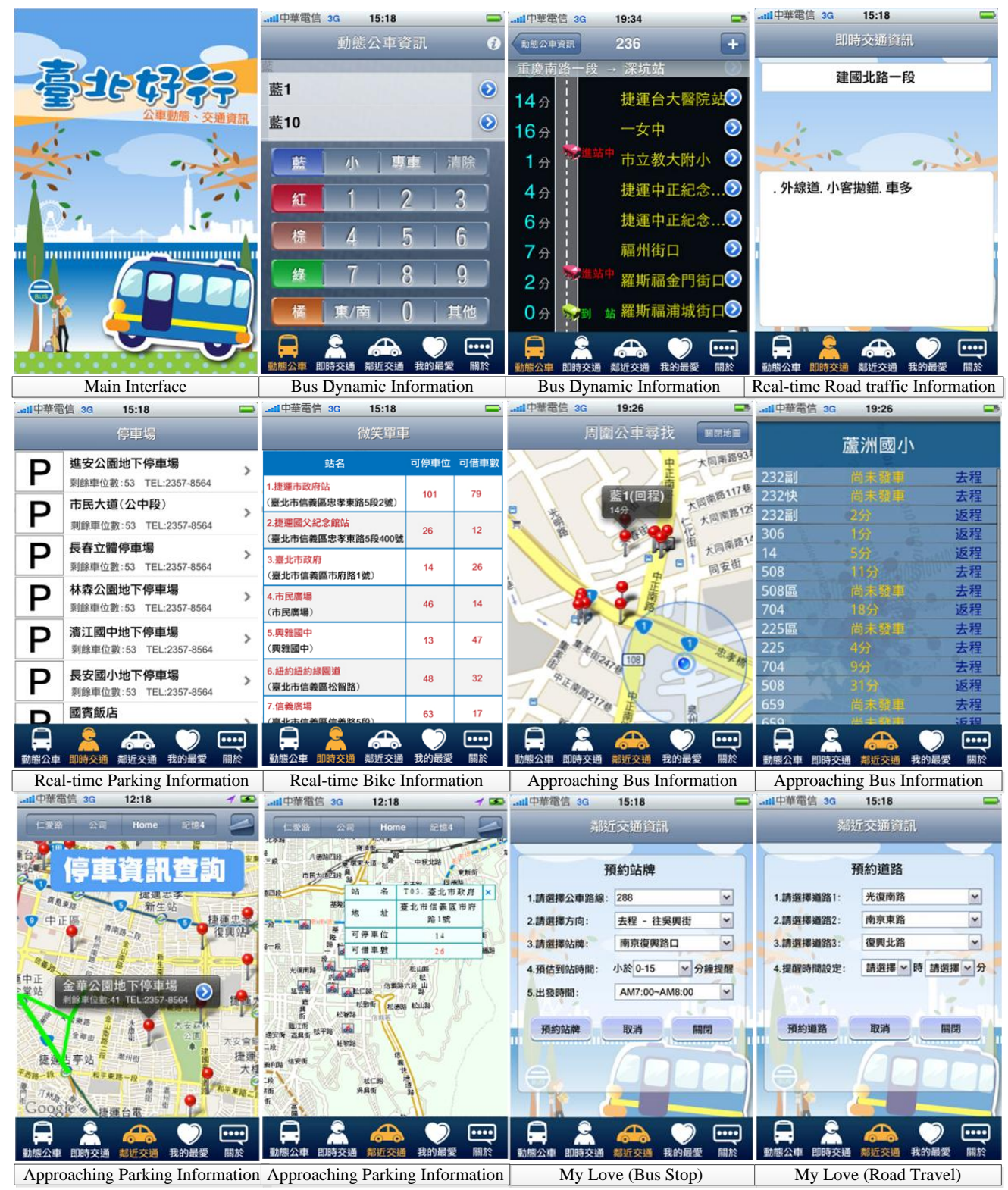

Fig. 3: Good Travel in Taipei's UI of Functional Modules 


\subsubsection{Instruction of Functional modules}

Good travel in Taipei's main interface have followed modules: (1) Bus Dynamic Information Query: Input the query bus, the App will display the bus's route and predicted arrival time between stations. (2) Real-time traffic query: Provided people with the real-time parking information (the amount of remaining parking spaces), real-time traffic information and "smiling cycling" information in Taipei. (3) Surrounding transportation resources query: Provide location-based services, show the users current location on the map and offer the information about the bus's predicted arrival time, the parking, the traffic condition and the "smiling cycling" surrounding. (4)Custom: Collect specific bus routes, "smiling cycling" rental, parking, and so on in the above query. In addition, two customization service, " the remind of bus arrival times " and "the real-time traffic condition of common routes", are provided in "Reservation".Above all shows in Fig.3 Good Travel in Taipei's UI(user interface) of functional modules.

\section{Analysis of Zhengzhou Public Travel Information Service Demand}

Zhengzhou is the capital and largest city of Henan province in north-central China. A prefecture-level city, it also serves as the political, economic, technological, and educational centre of the province, as well as a major transportation hub for Central China. The city lies on the southern bank of the Yellow River, and is one of the Eight Great Ancient Capitals of China. With $8,626,505$ inhabitants according to the 2010 census and $3,980,250$ in its built-up area ( 6 urban districts +5 City +1 County), the city is one of the main built up areas of Henan region. Zhengzhou is now a rapidly growing city, one of China's eight ancient capitals, Chinese Excellent Tourism city, and in this papers Zhengzhou is as an example in China to illustrate the Application of integrated traffic information service system for public travel based on smart phones.

\subsection{Large Number of Smart Phone Users in Zhengzhou}

According to the statistics of Ministry of Industry and Information Technology of the People's Republic of China [4], the number of mobile users in Zhengzhou has reached 9.283 million at the end of 2011. It can also be calculate base on the predicted smart phones penetration(In 2012, smart phones penetration to reach $38 \%$ ) which is given from the Frost Raadt \& Sullivan company in January 2011 that Zhengzhou currently smart phones users is over 3.5 million.

\subsection{Zhengzhou Traffic Information Construction Status}

The achievement of the construction of Zhengzhou city traffic information is significant. In public transport aspects: The Public Transport Corporation established and succession to improve the wisdom scheduling system, targeting on the bus's scheduling, management and monitoring, based on GPS from 2009. Also the transit information such as vehicles arrive time can be published though website, WAP mobile phone and station electronic screen. In summary, the information provision in the transit has a good foundation.

In the ITS, the Zhengzhou city government invested $¥ 89.16$ million Yuan in first-stage construction of urban intelligent traffic management system. The system includes six subsystems: Traffic signal control systems, traffic information collection system, traffic guidance systems, intelligent vehicle monitoring and recording (bayonet) system, traffic video surveillance systems, and traffic violation monitoring system. And second-stage of the project will total investment 90.8 million Yuan and add about 1200 detectors in 30 road 400 sections. ITMS (Intelligent traffic management system) will be divided into two parts, after the completion project it can satisfy the actual needs of the city road traffic management, at the same time solve the actual problems of the traffic management. The first batch of construction include auxiliary decision-making of traffic management and the simulation system, traffic information and public service platform, traffic information collection system (Continue to construction), traffic video monitoring system (Continue to construction), the traffic guidance system (Continue to construction), intelligent traffic integrated management platform (Continue to construction), with bidding in the middle of September, started construction in early October, and completion in late November, in 2011. The second batch of construction include vehicle intelligent monitoring and recording system, traffic signal control system, mobile police and PGIS (police geographic information system), the GPS positioning system, and transformation of the command center , etc. The construction plan bidding in Early October, begin construction late October, complete in December late. Zhengzhou city has set up and improve the traffic monitoring and information display system, in the future the platform will also link traffic of urban intelligent traffic management system, presenting the real-time traffic information on the platform. To sum up, Zhengzhou has provided well infrastructure in intelligent transportation, and is beneficial to construction of information integrated platform in the future.

\subsection{Zhengzhou Traffic Information Construction Status}

From the end of April 2011, Taipei City Department of Transportation begin to provide "Good Travel in 
Taipei " App in the App Store and Android Market. The APP involving Taipei dynamic traffic information (parking, real-time traffic, cycling ...), bus and subway interchange recommended, bus information and other information. At the end of June, the APP has been downloaded more than 80,000 times, once ranking NO.1 among the travel category in the App Store, which shows the urgent needs of the people to the realtime traffic information.

The Zhengzhou citizen is no exception, having strong demand for the static traffic facilities information and real-time traffic information before the trip and travel. However, the available way to deliver transportation information is very limited, mainly though the guidance screen (traffic guidance and Parking Guidance) and supplemented website, radio. Urban road traffic, bus, taxi, subway, airport and bus real-time information that citizens are unable to get, even the static transport facilities information are not be provided enough. In view of the urgent needs of the people over traffic information, making full use of and mining the Zhengzhou city's existing traffic information resources through the smart phone to widely distribute traffic information, enables people to keep abreast of the realtime traffic conditions of variety transport modes in the City, helping in planning travel routes, saving travel time and choosing transport mode, then improving the city's traffic operating efficiency.

\section{System Planning and Design}

\subsection{The Center of Traffic Information Integrated}

Now the Zhengzhou citizens who want to get traffic information have to respectively browse the websites of the various units. At the same time, in the websites the information such as subway, high-speed rail, Airlines and others which people will often use, need to expanded and integrated. And the information of Lane reduction or diversion caused by road construction also should be provided later. All in all, the integrated traffic information center can sum and post all available information, making the Zhengzhou public or even foreign people to obtain relevant information via the traffic information center as show in Fig.4.

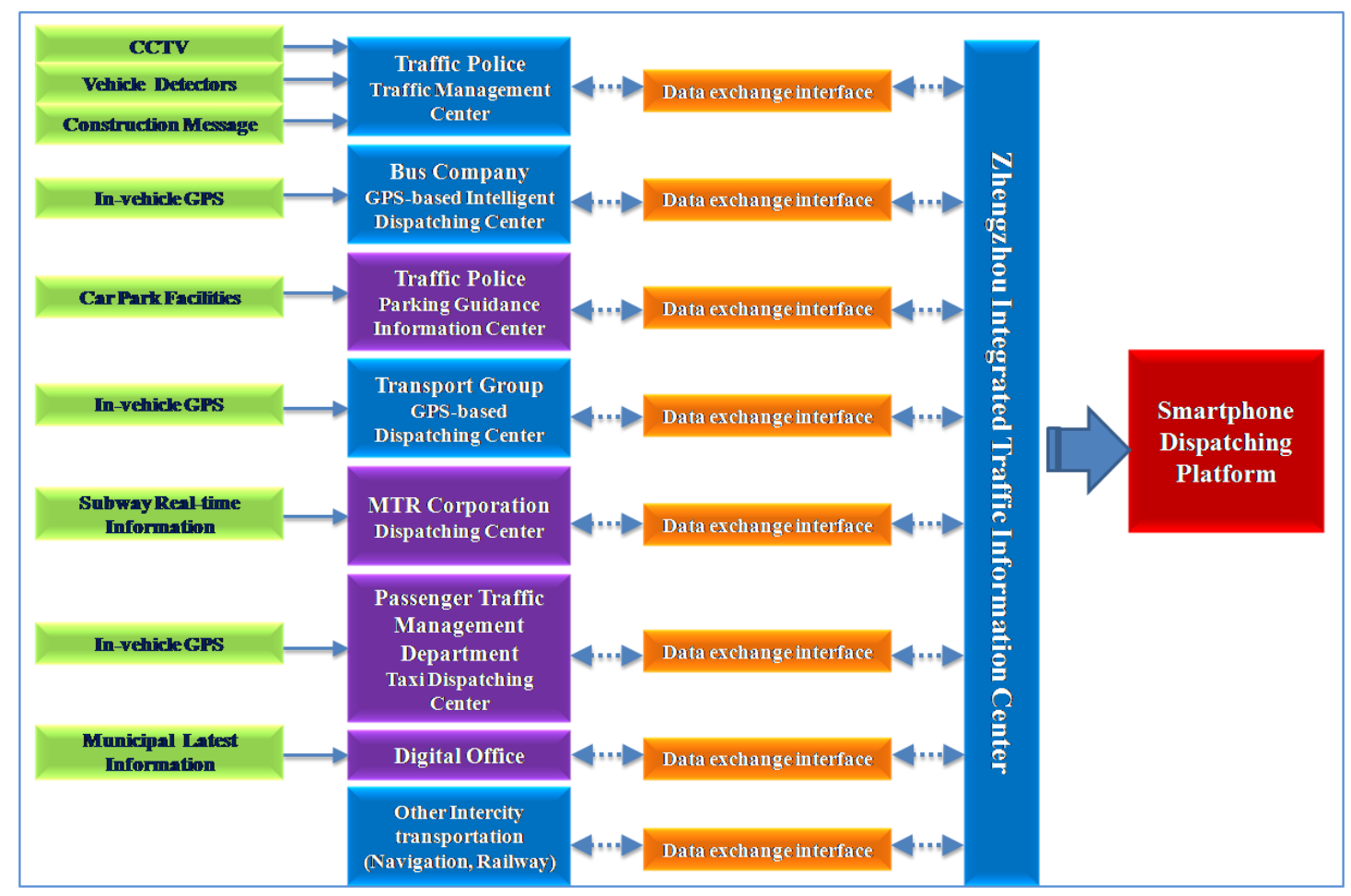

Fig. 4: The Future vision of Zhengzhou City Traffic Information Platform

For current Zhengzhou traffic information, this paper gives the plan and schedule of the traffic information aggregation and release as shown in the Table 1 . Described as follows: The GPS dispatch center of public transportation system basically completed can publish information; Traffic management system firststage is finished and available to provide real-time traffic information about the artery; The long-distance passenger transportation aspect now only provide static information such as hub station, bus terminal, routes and bus schedule; Parking part now can only provide static information such as parking location and parking numbers and so on; As the small demand for taxi information at this stage so it were not provided; Subway Information will be provided in the completion of the subway: Other intercity transportation is more simple, planning to provide in link Mode. 
Table 1: The Plan and Schedule of the Traffic Information Aggregation and Release

\begin{tabular}{|l|l|l|l|}
\hline \multicolumn{1}{|c|}{ Project Item } & \multicolumn{1}{|c|}{ Information } & \multicolumn{1}{c|}{ Source } & \multicolumn{1}{|c|}{$\begin{array}{c}\text { Information Provision } \\
\text { Currently }\end{array}$} \\
\hline Bus & $\begin{array}{l}\text { Station Locations, Real- } \\
\text { time Dynamic Information }\end{array}$ & Bus Company & $\begin{array}{l}\text { Bus Static and Dynamic } \\
\text { Information }\end{array}$ \\
\hline Road & $\begin{array}{l}\text { Velocity, Degree of Traffic } \\
\text { Jam, Video, Construction } \\
\text { Message }\end{array}$ & Traffic Police & $\begin{array}{l}\text { Part of Road Traffic } \\
\text { Information }\end{array}$ \\
\hline $\begin{array}{l}\text { Long-distance } \\
\text { Passenger } \\
\text { Transport }\end{array}$ & $\begin{array}{l}\text { Passenger Terminal } \\
\text { Locations, Route, Number } \\
\text { of Runs, Real-time } \\
\text { Dynamic Information }\end{array}$ & Transport Group & $\begin{array}{l}\text { Passenger Terminal } \\
\text { Locations, Route, } \\
\text { Number of Runs, }\end{array}$ \\
\hline Parking Lot & $\begin{array}{l}\text { Locations, Real-time } \\
\text { Vacant Position Number }\end{array}$ & $\begin{array}{l}\text { Parking } \\
\text { Management } \\
\text { Center }\end{array}$ & Locations \\
\hline Taxi & $\begin{array}{l}\text { Real-time Dial-a-cab } \\
\text { Service }\end{array}$ & $\begin{array}{l}\text { City Management } \\
\text { Office }\end{array}$ & Unavailable \\
\hline Subway & $\begin{array}{l}\text { Station Locations, Bus } \\
\text { Route }\end{array}$ & $\begin{array}{l}\text { MTR Corporation, } \\
\text { Bus Company }\end{array}$ & Unavailable \\
\hline Intercity Transport & $\begin{array}{l}\text { Railway, Highway and Air } \\
\text { Information }\end{array}$ & LINK to Webpage & $\begin{array}{l}\text { Provide Information by } \\
\text { LINK }\end{array}$ \\
\hline
\end{tabular}

Table 2: The Smooth Traffic in Zhengzhou Function Structure

\begin{tabular}{|c|c|c|c|}
\hline $\begin{array}{l}\text { Project } \\
\text { Item }\end{array}$ & $\begin{array}{c}\text { Data } \\
\text { Category }\end{array}$ & Data & Function \\
\hline \multirow{5}{*}{$\begin{array}{l}\text { Bus } \\
\text { Information }\end{array}$} & \multirow{3}{*}{ Static } & Route Inquiry & $\begin{array}{l}\text { Input link number, display stations on } \\
\text { simplified maps. }\end{array}$ \\
\hline & & Station Inquiry & $\begin{array}{l}\text { Enquire stations near fix location within } \\
\text { certain range. }\end{array}$ \\
\hline & & Transfer Inquiry & $\begin{array}{l}\text { Input start and end position coordinates and } \\
\text { plan feasible bus traveling track or feasible } \\
\text { bus transfer track. }\end{array}$ \\
\hline & \multirow{2}{*}{ Dynamic } & Arrival Distance & $\begin{array}{l}\text { Input link number and stations and inform } \\
\text { user of nearest distant to stations respectively. }\end{array}$ \\
\hline & & Latest News & $\begin{array}{l}\text { Bus transportation companies provide most } \\
\text { recent station information, including bus line } \\
\text { changes. }\end{array}$ \\
\hline \multirow{4}{*}{$\begin{array}{l}\text { Road } \\
\text { Information }\end{array}$} & \multirow{4}{*}{ Dynamic } & Average Speed & $\begin{array}{l}\text { Input selected road and display traffic states } \\
\text { between links in different colors (red, yellow } \\
\text { and blue; red means congestion). }\end{array}$ \\
\hline & & Construction Message & $\begin{array}{l}\text { Display recent construction information in } \\
\text { table format. }\end{array}$ \\
\hline & & Traffic videos & $\begin{array}{l}\text { Input selected roads, display real-time video } \\
\text { information (This function is unavailable due } \\
\text { to traffic management facility update). }\end{array}$ \\
\hline & & Latest News & $\begin{array}{l}\text { Traffic police provides most recent traffic } \\
\text { information, such as traffic incidents. }\end{array}$ \\
\hline \multirow{4}{*}{$\begin{array}{l}\text { Intercity } \\
\text { Transport }\end{array}$} & \multirow{3}{*}{ Static } & Route Inquiry & $\begin{array}{l}\text { Input selected links, display stations covered } \\
\text { by enquired line. }\end{array}$ \\
\hline & & Site Inquiry & $\begin{array}{l}\text { Input selected stations, display lines between } \\
\text { stations. }\end{array}$ \\
\hline & & Bus Lines Inquiry & $\begin{array}{l}\text { Input selected stations, display reachable } \\
\text { traffic lines near input stations. }\end{array}$ \\
\hline & Dynamic & Latest News & $\begin{array}{l}\text { Transportation Group provides most recent } \\
\text { bus information, such as lines adjustment. }\end{array}$ \\
\hline \multirow{2}{*}{$\begin{array}{l}\text { Parking Lot } \\
\text { Information }\end{array}$} & \multirow{2}{*}{ Static } & Parking Lot Inquiry & $\begin{array}{l}\text { Enquire surrounding parking areas based on } \\
\text { fixed location, and show Number of } \\
\text { remaining seats available. }\end{array}$ \\
\hline & & $\begin{array}{l}\text { Parking Lot Nearby } \\
\text { Inquiry }\end{array}$ & $\begin{array}{l}\text { Enquire surrounding parking areas based on } \\
\text { fixed location, and display them on GIS map, } \\
\text { enquiring range can be set. }\end{array}$ \\
\hline \multirow{3}{*}{$\begin{array}{l}\text { Airport \& } \\
\text { Railway }\end{array}$} & \multirow{3}{*}{ Dynamic } & $\begin{array}{l}\text { Railway Real-time } \\
\text { Dynamic Information }\end{array}$ & Links to Zhengzhou Railway Web sites. \\
\hline & & $\begin{array}{l}\text { High-speed Railway } \\
\text { Real-time Information }\end{array}$ & $\begin{array}{l}\text { Links to Zhengzhou High-speed Railway Web } \\
\text { sites. }\end{array}$ \\
\hline & & $\begin{array}{l}\text { Airport Real-time } \\
\text { Information }\end{array}$ & Links to Zhengzhou Airport Web sites. \\
\hline
\end{tabular}

\subsection{Content and Function}

Reference to other cases in different areas and according to existing data resources in Zhengzhou, The Smooth Traffic in Zhengzhou function structure of this stage has been initially studied and determined, as shown below. The overall framework is divided into five major areas: Public transportation information, Road condition information, Intercity passenger transportation, Parking information and The Airport Railway. Each field's data type, data content and $\mathrm{g}$ function, specified as follows in Table 2.

\subsection{System Architecture}

\subsubsection{System Architecture}

Integrated platform obtains the required data from variety of data sources, stored them in the data center, and provide various traffic information services through the smart phone. The system architecture includes the preceding traffic data collection, data processing center and the Application layer publishing the traffic information. Its structure is shown in Fig. 5.

\subsubsection{The Traffic Information App}

The following Fig.6 illustrate the main functions of the App: "Transit information", "road information", "intercity passenger", "parking information" and "airport and railway". The features above can meet the user' demand anytime:

The App obtains the data from integrated platform servers via Web Service technology then presents in Appropriate way (Listing, Web View, Map, Routes). It also can help users to find the target on the map using the phone's GPS and map API (API, Application Programming Interface) (Baidu or Google). Fig.7 Illustrations the communication between the APP and with integrated platform.

\subsection{Integrated Platform}

Main tasks: 1 providing the desired information and data of the "smart phone traffic information software".2 Obtain useful data from the transport data sources and store them in the database for phone's API. 3 provide system management functions (data analysis, user feedback, system parameter setting). The integrated platform function is shown in the Fig.8:

Data: Use Web Service technology to develop the APP's API including Transit information API, Road information API, Intercity Passenger API, Parking information API and System related API, and use JSON (Javascript Object Notation) as the data transfer format. JSON is a lightweight data-interchange language, textbased, easily to read and modify, with high compatibility. Many programs have a corresponding in the programs library. 

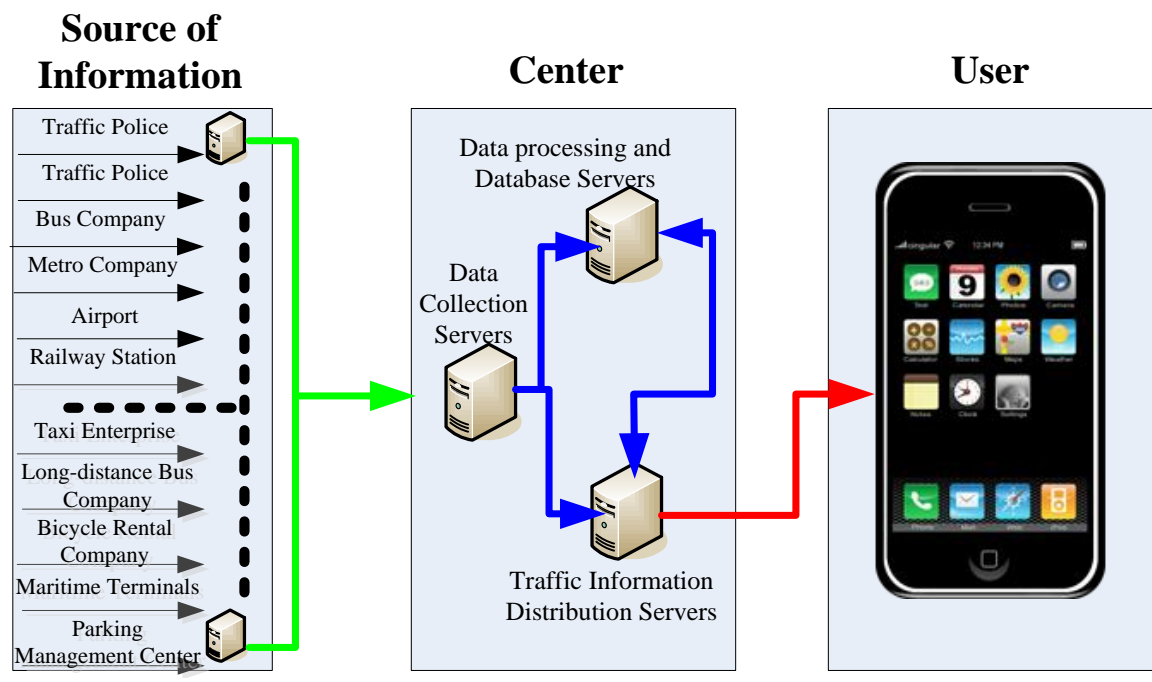

Fig. 5: System Architecture

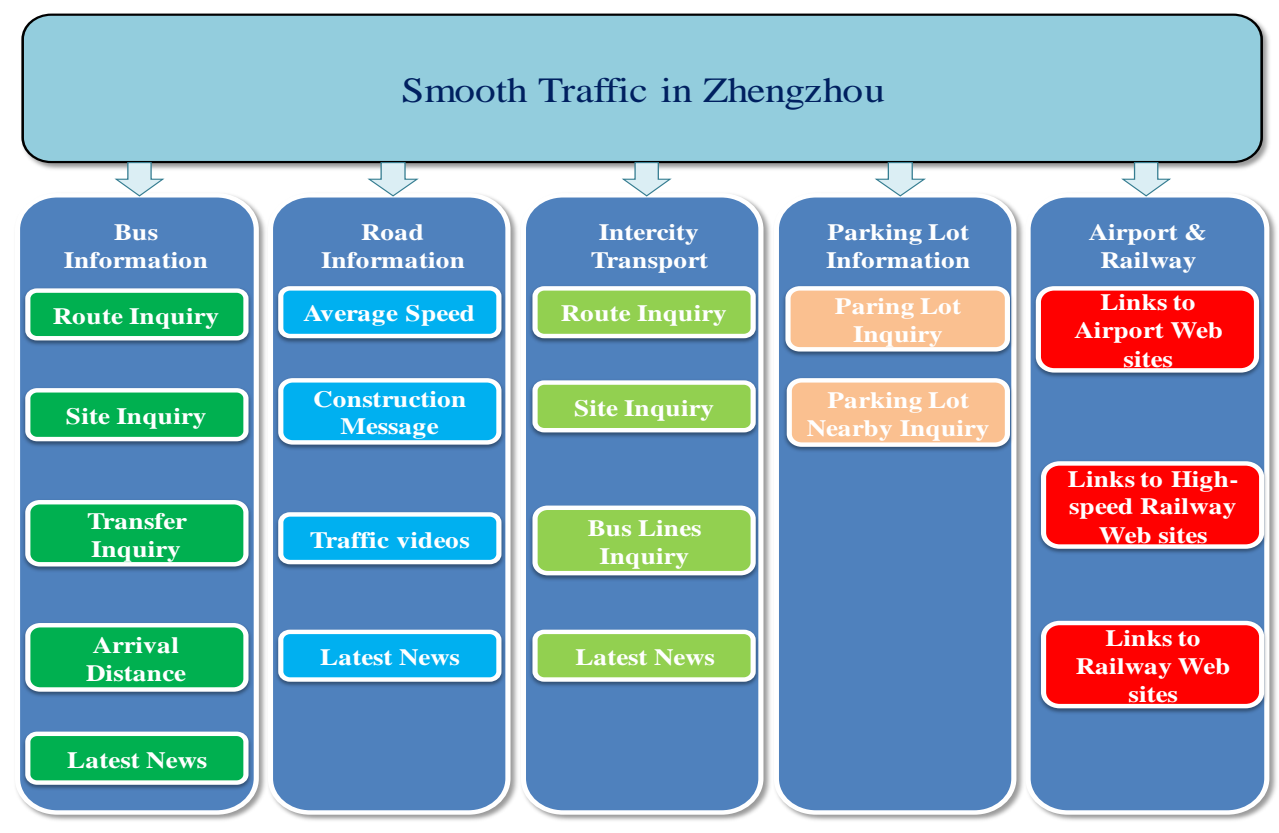

Fig. 6: The main functions of the APP-Smooth Traffic in Zhengzhou

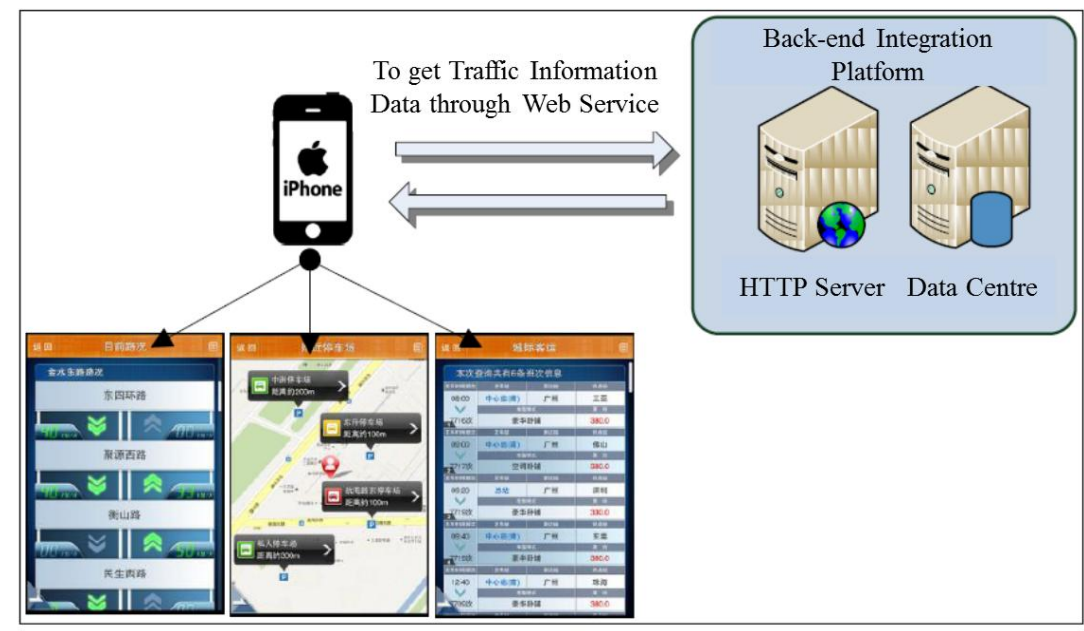

Fig. 7: Illustration of Communication between the APP and Integrated Platform 


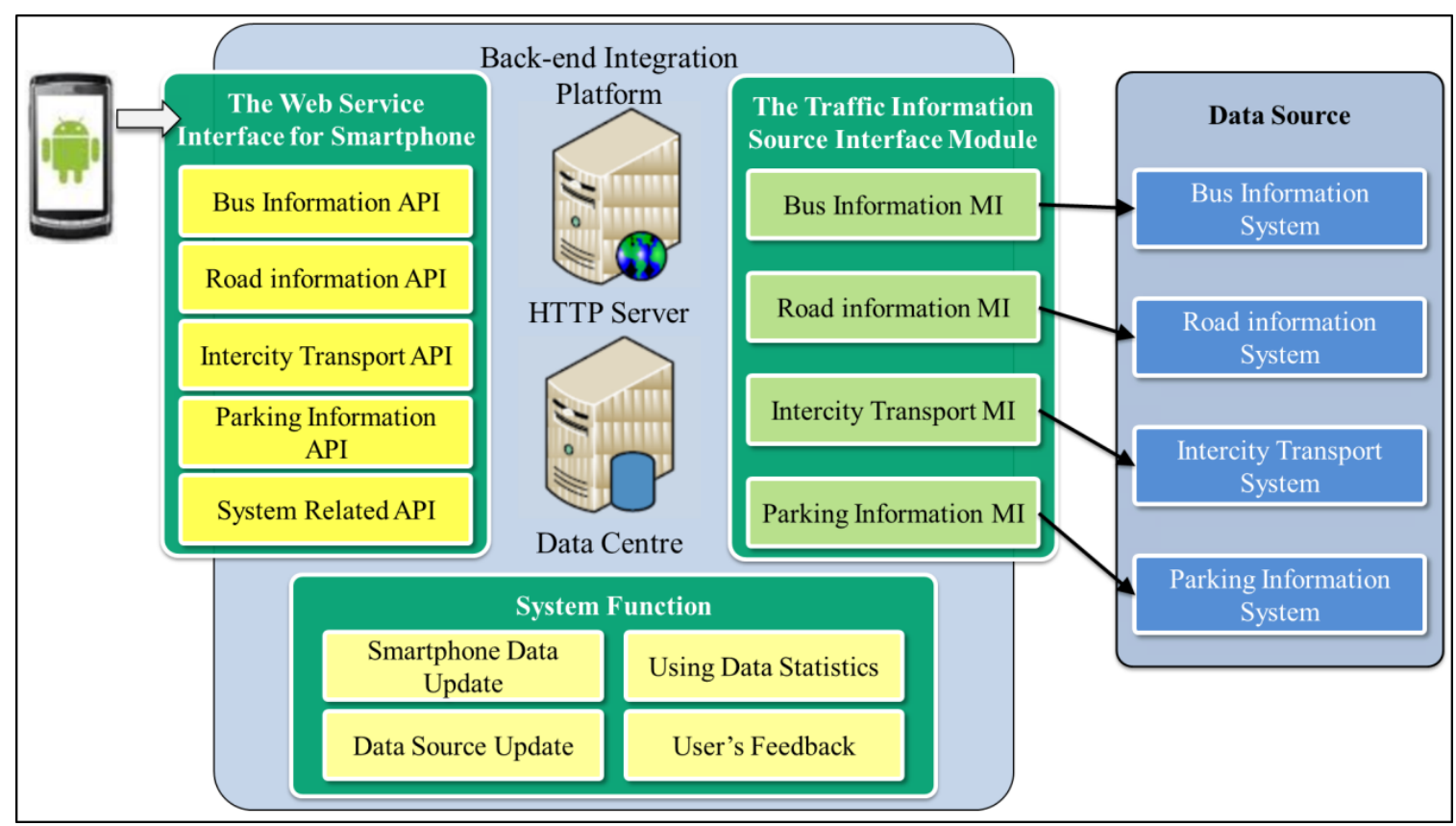

Fig. 8: The Integrated Platform Function

Connection with the data sources: The system make technical discussions with the data sources though two communication way: Web Service, TCP / IP and in JSON transmission formats. Data acquisition efficiency: In order for the data communications will be more efficient between integrated platform and data sources. The system depending on the characteristics of the data divide the information into intensive updated and nonintensive updated, in order to update in Appropriate time and disperse the load of the network and servers. For example: The latest news: update every 10 to 30 minutes (adjustable), Non-real-time data: update from all data sources in 12:00 AM 1:00 AM each night. $n$ real time data: Update depending on the update frequency of the data source.

System management: system initially can provide Data analysis, User feedback, System parameter setting and other functions.

\subsection{UI Interface Design}

User-friendly designed of the UI interface ensuring the App-traffic information service system has the ability to make more users accepted and benefited. Combined with the ingenuity of experienced engineers and graphic designer and integrated the overall style and operating, there are several style of the APPSmooth Traffic in Zhengzhou, as shown in Fig.9.

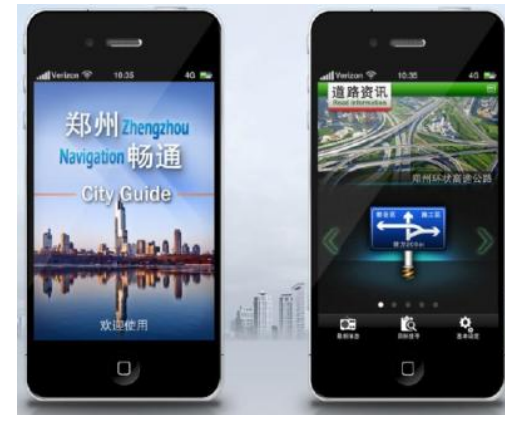

Style 1

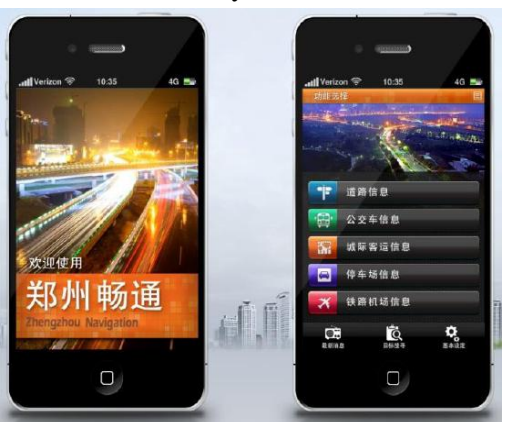

Style 2

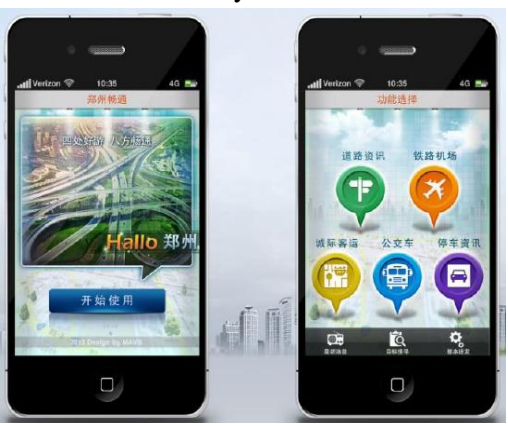

Style 3

Fig. 9: UI design of the APP-Smooth Traffic in Zhengzhou 


\section{Conclusion}

The goal of "Good Travel in Taipei" is to provide comprehensive and integrated transport information, concluding Taipei major means of transportation, road traffic conditions, transfer information and so on in an APP, making users to master Taipei traffic information and meet the needs of their travel planning. Learn from "Good Travel in Taipei" concept, the paper proposes a Zhengzhou traffic information service system architecture based on smart phone APP. This system can provide a wide range of traffic information in Zhengzhou, such as transit information, road traffic conditions, parking information Airport Railway and others. Free traffic information allows users to fully master the traffic information in Zhengzhou, including static information and dynamic information and plan travel.

\section{Acknowledgments}

The authors luckily took part in the job which is involving in Zhengzhou Integrated Traffic Information Service System for Public Travel plan, design and building, especially in Based on Smart Phones Applications. And we wish to thank Zhengzhou Urban Planning Bureau, Zhengzhou Bus Group, and Zhengzhou Traffic Police etc give the chance to achieve the practice of the system.

\section{References}

[1] Communication Information News. (2010). "iPhone flip the smartphone craze and the three major trends development showed of smart phone."

<http://news.yesky.com/416/11394916.shtml>

(Sep. 8, 2012).

[2] DEVX Staff. (2010). "25 Billion Mobile App Downloads by 2015.", <http://www.devx.com/DailyNews/Article/45185?t $\mathrm{rk}=$ DXRSS_LATEST $>$ (April 10, 2012).

[3] ZHOU Chong-hua, GAO Zuo-gang, XU Chen and SU Zhi-zhe. (2012) "Research on Traffic Information Service System for Public Travel Based on Smart Phones Application" [J]. Traffic \& Transportation, 2012(z1), p77 79. (in Chinese).

[4] Zhengzhou Bureau of Statistics, Henan survey organization national bureau of statistics information network. (2012). "2011 Zhengzhou City, the national economy and social development statistical bulletin". < http://www.ha.stats.gov.cn/hntj/tjfw/tjgb/sxsgb/w ebinfo/2012/03/1332823947537928.htm>

(Nov.30,2012).

\section{Authors' Profiles}

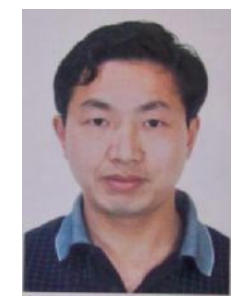

Chonghua Zhou (1977-), male, was born in Hengyang, Hunan Province, China, in April 1977. He received the Master's degree in Traffic Information Engineering and Control from Tongji University in 2005.

From 2005 to now, he works in Thi Shanghai Consultants INC. And he has published near 20 first-author technical papers and takes part in about 30 projects such as Research on Informationization and Intelligentization Planning and Key Technologies for ShangHai Road Network, Research on Vehicle Position System (VPS) in Development Countries and Regions, Research on Planning, Design and Building for Jinan BRT etc.

His personal research domain and interests are Intelligent Transportation System (ITS), Transit Planning and Traffic Control, etc. His previous publications include: A Real-Time Information System for BRT Based on GPS/Signpost Compound Navigation technology (Wuhan, Proceedings of the LEITS2010, 2010), Modeling ETC lane Deployment Based on Queuing Theory and Incremental-Benefit-Cost Ratio Maximum (Beijing, JOURNAL OF TRANSPORTATION SYSTEMS ENGINEERING AND INFORMATION TECHNOLOGY, Vol.9(5), 2009), Next Road Pricing Technologies Studying Based on VPS (Beijing, 4th China Annual Conference on ITS, 2006), BUS FLEET MANAGEMENT SYSTEM FOR BRT BASED ON PLATFORM SCREEN DOORS(Wuhan, Proceedings of the ICTIS 2011, 2011), Interface between Vehicles and Stations for Bus Rapid Transit Systems (Nanjing, Proceedings of the ICCTP 2011, 2011), Research on Traffic Information Service System for Public Travel Based on Smart Phones Application (Shanghai, Traffic \& Transportation, 2012(z1), 2012) etc.

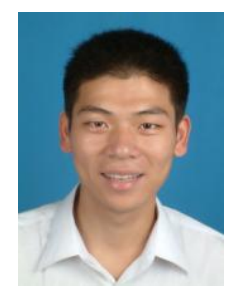

Zhiyong Weng (1981-), male, Shanghai, China, Master, his research directions include smart city and intelligent transportation control system design.

Chen XU (1984-), male, Jiamusi, China, Master, his research directions include intelligent transportation control system design and system optimal.

Zhizhe SU (1968 - ), male, Taipei, Master, Senior Engineer, his research directions include transportation plan, intelligent transportation control system design and system optimal. 